\title{
PARTIDOS POLÍTICOS, REDES CORPORATIVAS Y FORMACIÓN DE GABINETES EN COSTA RICA: 1986-2010
}

\section{POLITICAL PARTIES, CORPORATE NETWORKS AND CABINET FORMATION IN COSTA RICA: 1986-2010}

\author{
Randall Blanco Lizano*
}

RESUMEN

El artículo discute aspectos centrales del debate sobre partidos políticos y redes de poder, se concentra en analizar empíricamente la presencia de tales actores dentro de los partidos políticos y su presencia determinante en la formación de los gabinetes en el gobierno costarricense.

Además, destaca las alianzas entre socios de CINDE, CEFSA y la Academia de Centroamérica, quiénes controlan las instituciones estatales vinculadas con el sector exportador desde 1986 hasta 2010 y discute los límites de la democracia procedimental al permitir tales tendencias corporativas.

PALABRAS CLAVE: COSTA RICA * PARTIDOS POLÍTICOS * REDES DE PODER *
CORPORATISMO

\section{ABSTRACT}

The paper discusses key aspects of the debate on political parties and power networks, focusing empirically analyze the presence of such actors within political parties Liberación Nacional y Partido Unidad Social Cristiana and their presence on the formation of cabinets in the Costa Rican government. Highlights CINDE alliance partners, CEFSA and the Central American Academy, who control the state institutions linked to the export sector from 1986 to 2010. It discusses the limits of procedural democracy to allow such corporate trends.

KEY WORDS: COSTA RICA * POLITICAL PARTIES * POWER NETWORKS * CORPORATISM

Escuela de Sociología de la Universidad de Costa Rica (UCR).

Escuela de Planificación Económica y Promoción Social de la Universidad Nacional (UNA).

randall.blanco@gmail.com 


\section{INTRODUCCIÓN}

Un número importante de investigaciones costarricenses $y$ latinoamericanas concentran sus debates sobre temas vinculados a la vigencia de la democracia en el país o en el continente, con una agenda que se mueve entre dos líneas fundamentales: aquellas dirigidas con los enfoques de gobernabilidad, que se preocupan centralmente por comprender las causas de los así llamados "déficits democráticos", o por comprender las causas de los fallos del mecanismo democrático, apelando a una especie de "mecánica institucionalista", que permitiría hacer ajustes al "sistema" o a corregir los "desequilibrios", con más o menos participación ciudadana, más instituciones 0 mejores controles políticos, con escasa profundidad crítica e interpretativa, en su mayoría análisis de carácter formalista o institucionalista.

Por otro lado, están los estudios basados en interpretaciones políticas, históricas y sociológicas, los cuales concentran sus análisis en tratar de entender las causas de la acción política de los movimientos sociales, actores políticos diversos, el papel determinante que han jugado en los así llamados "procesos de transición a la democracia" y su papel dinámico y cuestionador de los regímenes de dominación oligárquica junto a las nuevas tareas políticas de tales actores y movimientos en lucha contra todo formalismo democratizante.

Este artículo se coloca en la segunda vertiente analítica, pero relevando el peso de los actores corporativos en el marco de las democracias procedimentales latinoamericanas, en este caso, en la situación costarricense, pero concentrando los análisis empíricos en la presencia de tales actores dentro de los partidos políticos y su presencia determinante en la formación de los gabinetes, con el objetivo de visibilizar sus redes de poder y sus capacidades de concentración de recursos para legitimar sus intereses sectoriales como expresión de la difusa "voluntad general", piedra de toque de las democracias procedimentales.

El artículo discute, por tanto, algunos antecedentes de investigaciones teóricas sobre la política, los procesos de formulación de políticas y los partidos políticos, algunas reflexiones latinoamericanas y resultados de investigaciones costarricenses sobre las dinámicas de los mismos, los conceptos y las prácticas corporativas, centrándose en el caso costarricense, mostrando sus vínculos con los partidos políticos y los notables recursos de poder con que cuentan para "ganar siempre", aunque nunca sometan sus nombres al escrutinio popular.

\section{POLÍTICA Y PARTIDOS POLÍTICOS}

En una de sus definiciones clásicas, David Easton describió la política como "la asignación autoritaria de valores para una sociedad". De tal definición, interesa destacar el papel preponderante que le asigna Easton al ejercicio autoritario como característico de la política, en este caso, hasta los valores societales resultan una expresión de tal práctica.

Se destaca a Easton, porque hasta un representante clásico del funcionalismo sistémico, no deja de reconocer uno de los componentes esenciales del análisis político y lo relaciona directamente con el ejercicio de autoridad. Y esa autoridad es también legitimidad del sistema y por ende, garantía de aceptación por aquellos a quienes se les asignan valores de manera autoritaria. La contrapartida, sería determinar quiénes son los asignadores de tales valores y con qué recursos cuentan para hacer valer tales "asignaciones".

Esta línea de interpretación lleva a Harold Laswell (citado por Aguilar Villanueva, 2003), quién resumía las preguntas básicas del análisis político en el conocido lema de "¿Quién obtiene qué, cómo lo hace y cuándo lo hace?”.

$\mathrm{Y}$ es que esta perspectiva empírica implica alejarse de todo tipo de estudio formalista o institucionalista de la política, de los procesos de formulación de políticas y el accionar de los partidos políticos, así como orienta a la reflexión y a la investigación para buscar respuestas concretas a tales interrogantes.

Alcántara Sáez (2004: 22), insiste en la necesidad de concentrarse en el estudio del 
partido político como unidad de análisis, sosteniendo su argumento en los postulados de Panebianco:

Aunque los trabajos se mulltiplicaron, Panebianco se había encargado de recordar en qué medida el análisis de los partidos como organizaciones complejas estaba todavía en la infancia.

En Costa Rica, los estudios de los partidos y sobre los partidos políticos como organizaciones complejas, todavía resienten ese estado "infantil" al que refería Panebianco desde hace 30 años. Especialmente en lo referido a los grupos de poder que se insertan dentro de los partidos políticos; por lo cual hace falta estudiar: ¿cómo se organizan desde fuera?, ¿cómo permean decisiones desde dentro?, ¿cómo estos utilizan las organizaciones partidarias para llevar adelante sus fines sectoriales en las agendas $y$ en las plataformas programáticas de los partidos?, ¿cómo, una vez que los partidos ganan las elecciones, se garantizan cuáles representantes significativos de los grupos de poder pasan directamente a cargos públicos en el poder ejecutivo o legislativo? y ¿cómo se rearticulan sus intereses en amalgamas complejas de intereses privados y "públicos"?

Abal Medina (2002: 43) retoma con claridad los desafíos propuestos por Katz y Mair para el estudio de los partidos políticos:

A diferencia de lo que ha ocurrido en otras áreas del estudio de los partidos políticos, continuamos conociendo sorprendentemente poco sobre las organizaciones partidarias (Katz y Mair, 1992: 2). Mientras entendemos bastante sobre los partidos y sus votantes, los partidos $y$ sus gobiernos y los partidos y sus competidores, sigue habiendo severos límites al entendimiento comparativo sobre cómo las organizaciones partidarias trabajan, cambian y se adaptan (Katz y Mair, 1994: 2). Como señalaba acertadamente Panebianco hace más de quince años, en cierto momento de la historia de la investigación científica sobre los partidos se ha producido una censura (Panebianco, 1990: 13) que la apartó de su interés originario sobre las organizaciones partidarias en sí mismas y la condujo hacia otros derroteros teóricos.

Este artículo se interesa en entregar un aporte de uno de los aspectos menos estudiados en las investigaciones costarricenses y centroamericanas sobre los partidos políticos, mostrando en perspectiva histórica, el papel de las redes de poder de sectores empresariales y tecnocráticos dentro de los partidos políticos costarricenses y su presencia determinante en los gabinetes del poder ejecutivo, en especial, en los sectores vinculados a las decisiones de políticas económicas y exportadoras.

Con ello se espera contribuir a superar esa especie de "censura" y de "edad infantil" de los estudios sobre partidos políticos como organizaciones complejas que señalaba Panebianco, retomar con fuerza las tesis de Katz y Mair sobre la necesidad de estudiar las organizaciones partidarias en toda su complejidad, para tratar de entender "cómo trabajan, cambian y se adaptan".

Se considera que aquí existe toda una agenda de investigación abierta para las Ciencias Sociales costarricenses y centroamericanas.

\section{DECISIONES POLÍTICAS Y ANÁLISIS DE POLÍTICAS PÚBLICAS}

Como en todo esfuerzo de creación de contextos interpretativos, la selección de los autores no pretende ser exhaustiva ni dar cuenta de "todos" los elementos del debate. La selección de autores y temas se ajusta a las necesidades de la investigación de sentar algunos de los ejes temáticos de la discusión.

Hay que señalar que existe coincidencia en una buena cantidad de especialistas en el campo de las Ciencias Políticas y la Sociología en reconocer el valor y la importancia del análisis de políticas públicas para la comprensión del fenómeno político. Sin duda, muchos de esos trabajos se sostienen desde la perspectiva 
clásica del public policy y sobre ello se refieren con deferencia y reconocimiento.

Pese a este reconocimiento, también existen coincidencias en caracterizar el análisis de política pública con una perspectiva crítica del modelo clásico del public policy, enfoque que es cuestionado por su carácter formalista $y$ unidireccional. Este enfoque sostiene nuclearmente que lo público lo produce el Estado y sus representantes como los únicos legitimados para la toma de decisiones.

Con mayores o menores intensidades los autores ofrecen perspectivas que identifican el análisis de política pública como un ejercicio complejo, multidimensional, dinámico y que funciona con diversidad de actores ${ }^{1}$ en variedad de niveles $y$ arenas.

Hay una diferencia sustantiva que establecen autores como Grindle y Thomas (1991), quienes elaboran y proponen un modelo interpretativo de carácter estructural que relaciona dos grandes variables, es decir, las relaciones entre decisiones públicas y cambios políticos y en ese contexto de complejidad realizan los análisis de políticas públicas.

El nudo del enfoque de Grindle y Thomas está en la propuesta epistemológica formulada en el libro Public Choices and Policy Change (Grindle y Thomas, 1991: 4) y que para esta investigación resultó de particular interés: existen diferencias notables entre las lógicas económicas y las lógicas políticas, pero ambas están estrechamente interrelacionadas ${ }^{2}$.

1 Los trabajos clásicos del análisis de políticas públicas refieren centralmente al concepto de actores políticos, aquí no se discutirán otros abordajes existentes como el concepto de agentes de Bourdieu.

El debate académico y político sobre las relaciones entre economía y política ocupa el centro de las discusiones entre economistas y sociólogos desde hace siglos. Para Bourdieu (estructuras sociales de la economía), o Hirshmann (retóricas de la intransigencia), se trata de dos disciplinas complementarias, aunque se señala que Bourdieu insiste en la necesidad de la crítica a fondo de los supuestos de la economía neoclásica, posición que se comparte aunque aquí no sea desarrollada.
El problema reside en mostrar concretamente cómo se dan esas múltiples interrelaciones entre ambos niveles, donde no existe automatismo, mecanicismo, ni sobredeterminación de una dimensión sobre otra.

Y eso es así, porque la dimensión económica ni la dimensión política son esencias reificadas, sino fenómenos multidimensionales y expresión de fuerzas sociales históricas concretas, que se encuentran imbricadas, actúan $y$ deciden con recursos de poder, estrategias discursivas, estrategias de dominación y legitimación extraordinariamente complejas.

Acercarse a la comprensión estructural de tales interrelaciones supone todo un desafío a resolver en la investigación sociológica, politológica y económica costarricense. De ahí la importancia de enfoques estructurales como el de Grindle y Thomas, dónde se establecen vínculos multidimensionales entre lógicas económicas y lógicas políticas.

\section{OPACIDAD DEL EJERCICIO DEL PODER Y NECESIDAD DE VISIBILIZARLO}

Para Lindblom (1991), la política es un proceso complejo, multidimensional, claroscuro (es una expresión dominante en el autor cuyo simbolismo se interpreta como un llamado de atención consistente a no dejarse deslumbrar por los "hechos evidentes y mecanicistas" del positivismo acrítico de las Ciencias Políticas tradicionales) que encubre $y$ descubre intereses $y$ poderes.

Gracias a esa capacidad de superar la inmediatez, Bourdieu (1997: 180) denomina a la sociología como una "ciencia de lo oculto" o Elias (1982: 68) la definía como una ciencia "cazadora de mitos", definiciones que permiten a la disciplina sociológica contar con herramientas teóricas y metodológicas suficientes para la comprensión de los fenómenos políticos.

Para Lindblom (1991), el reconocimiento explícito de la influencia consistente y constante de los intereses privados en la definición de las prioridades de lo público, lo lleva a alejarse 
notablemente del enfoque formalista del public policy.

Este aspecto es de particular interés en este artículo, ya que nos permite mostrar una aproximación al estudio de los grupos de interés particular y sus recursos de poder para influenciar sus nombramientos en los distintos gabinetes y poder así incidir directamente en la formulación y elaboración de políticas públicas en Costa Rica.

Para otros autores como Meny y Thoenig (1992), el Estado no actúa solo ni es una entelequia abstracta esencializada, sino que siendo expresión de una multiplicidad de intereses y fuerzas, sus expresiones institucionales actúan con otros actores e interlocutores, donde los actores privados juegan normalmente papeles determinantes.

Cada sociedad recurre a múltiples formas de tratamiento de sus problemas colectivos, entre los cuales la esfera pública representa solo una de sus posibilidades y finalmente, reconocen que la naturaleza de lo político debe ser una cuestión central para las Ciencias Sociales que no puede darse por sentada ni constituye un dato.

En el centro del debate y el análisis están las relaciones entre Estado y sociedad: no como esencias sino como espacios de luchas de poder de actores diversos en sociedades concretas.

En este artículo se ofrecen materiales teóricos y empíricos que se dirigen a visibilizar el peso de los actores empresariales en los dos partidos políticos dominantes, en las arenas político-electorales costarricenses: el partido Liberación Nacional y el Partido Unidad Social Cristiana en el período comprendido entre las elecciones de 1986 y las elecciones de 2010.

\section{ALGUNOS ANTECEDENTES DE LA INVESTIGACIÓN COSTARRICENSE}

El énfasis de los estudios costarricenses sobre el sistema político se orienta hacia cuestiones del funcionamiento del sistema de partidos políticos, comportamiento electoral, abstencionismo político, financiamiento de partidos, legislación electoral y análisis sobre los ciclos electorales; más recientemente, proliferan estudios del nivel municipal y primeros aportes sobre las dinámicas de la ingeniería electoral y los comportamientos electorales.

Se podrían destacar una serie de aportes que se han ido aproximando a la comprensión de las lógicas complejas de las dinámicas de sectores privados y la existencia de sectores tecnocráticos (equipos económicos, comunidades epistémicas) que permiten entregar antecedentes de valor para las investigaciones costarricenses.

Sojo (1991, 1992), desarrolla a inicios de la década de los noventa del siglo $\mathrm{xx}$, una serie de estudios que permiten identificar el peso de las influencias de la Agencia para el Desarrollo Internacional (AID) de los Estados Unidos en el fortalecimiento de los sectores privados en Costa Rica.

Raventós Vörst (2001), identifica el papel estratégico jugado por los "equipos económicos" en el fortalecimiento de las tendencias privatizantes en Costa Rica y cómo camuflaban sus decisiones $y$ opiniones "como presiones de los organismos financieros internacionales", con lo que sus responsabilidades políticas quedaban lejos del escrutinio de la ciudadanía.

El trabajo de Solís Avendaño (2002), plantea algunas hipótesis sobre la cultura y el comportamiento político de los costarricenses tomando como base de análisis las luchas políticas contra la privatización del Instituto Costarricense de Electricidad (ICE) durante las protestas contra el denominado "combo del ICE". El autor destaca el papel abiertamente corporativo del proyecto de ley y muestra el papel jugado por los partidos Liberación Nacional y Unidad Social Cristiana en su diseño, elaboración, tramitación y votación.

La Tesis de Maestría en Sociología de Vásquez (2008), entrega un estudio de la presencia históricamente mayoritaria de las cámaras patronales en instituciones económicas, financieras y políticas, concentrándose en un estudio de la Promotora de Comercio Exterior de Costa Rica (PROCOMER). 
Según el autor, tal monopolio de la representación por parte de las cámaras lesiona estructuralmente la calidad de la democracia costarricense $y$ urge desarrollar acciones que permitan eliminar tales monopolios.

El trabajo de Molina Alfaro (2009), privilegia el concepto de comunidades epistémicas y se centra en el análisis del equipo negociador costarricense del Tratado de Libre Comercio Centroamérica-República Dominicana-Estados Unidos para concluir que:

En el caso del equipo negociador del TLC, éste a partir de una socialización educacional e institucional común se constituyó y actuó como una comunidad de pensamiento que se apropió de un campo de política específico. Las ideas se constituyeron en elemento clave, a través del cual los negociadores imprimieron su visión en la política de comercio exterior $y$; el saber experto generado se constituyó en un recurso de poder que les permitió emerger como un actor diferenciado en la política costarricense y ascender profesionalmente.

Se señala que la investigación al privilegiar tal categoría, no analiza las relaciones complejas que establecieron tales equipos con los partidos políticos y el peso determinante que tuvieron sus vínculos con los sectores empresariales costarricenses y con intereses financieros internacionales.

Finalmente, trabajos anteriores (Blanco, 2004, 2010a, 2010b) muestran consistentemente la existencia de redes corporativas relacionadas con distintos sectores de la institucionalidad pública costarricense y con el uso de los recursos patrimoniales o de los presupuestos públicos para garantizar recursos de control, de dominación y mecanismos de acumulación para tales redes, lo que representa un cuestionamiento profundo de los límites de la democracia representativa, al existir las leyes, procedimientos e instituciones que permiten y facilitan tal usufructo corporativo de los bienes patrimoniales de la colectividad.
Según una investigación anterior se dice que:

Aquí utilizamos la expresión corporatismo para referirnos al surgimiento de un conjunto de organizaciones de intereses privados que fueron creadas en el contexto de los procesos de reforma del Estado en Costa Rica durante las últimas dos décadas del siglo xx, surgimiento de organizaciones corporativas que tienen dos características peculiares para el caso costarricense: son una mescolanza de agentes privados $y$ públicos que han constituido asociaciones o fundaciones privadas, declaradas de "interés público" para legitimar la gestión privada de los intereses públicos, $y$, [sic] por otro lado, han hecho del control del aparato del Estado una condición de existencia estructural para el desarrollo y consolidación de las organizaciones corporativas (Blanco, 2010b: 4).

Tales estudios (Blanco, 2004) se concentran en las redes corporativas relacionadas con el usufructo de los recursos de la biodiversidad costarricense, en especial, de las prácticas corporativas del Instituto Nacional de Biodiversidad (INBio), de las prácticas corporativas de la Fundación Omar Dengo en el caso del sector de informática educativa y de las dinámicas de las redes corporativas del sector exportador costarricense (Blanco, 2010a) en la mescolanza de intereses públicos y privados, de la Coalición de Iniciativas de Desarrollo (CINDE) en relación con el Ministerio de Comercio Exterior (COMEX) y en general, del dominio monopólico ejercido por socios de CINDE en las principales instituciones públicas vinculadas con las decisiones sobre políticas económicas y exportadoras.

\section{REDES DE PODER, PARTIDOS POLÍTICOS Y FORMACIÓN DE GABINETES 1986-2010}

Concluidas las reflexiones teóricas y de revisión de antecedentes de investigación que 
han permitido perfilar el objeto de estudio de este artículo, se continúa con la presentación de resultados de estas indagaciones empíricas para finalmente, ofrecer una serie de conclusiones generales sobre la importancia de abordajes como el propuesto. Lo anterior para la comprensión de una de las dimensiones de los partidos políticos como organizaciones complejas, al decir de Panebianco; aquella relacionada con redes de poder y sus capacidades de influencia en los partidos políticos costarricenses.

Se quiere presentar una visión histórica de las redes de poder, sus relaciones con los partidos políticos Liberación Nacional y Unidad Social Cristiana, indagando la presencia de tales representantes de redes en la conformación de los gabinetes de 1986 al 2010.

\section{REDES DE PODER DEL SECTOR EXPORTADOR EN COSTA RICA}

Mucho del trabajo de diseño y orientación de las políticas de fomento a las exportaciones y la atracción de inversiones en el nuevo modelo económico costarricense de libre comercio, estuvo bajo la dirección de una serie de organizaciones privadas como la Academia de Centroamérica, la empresa Consultores Económicos y Financieros Sociedad Anónima (CEFSA) y el CINDE.

La Academia de Centroamérica es un grupo de profesionales economistas y abogados, fundada a inicios de la década de los 70 del siglo $\mathrm{xx}$, la mayoría de ellos de formación liberal que fueron evolucionando a posiciones neoliberales y que desde sus inicios mantuvieron una posición constante de críticas a la intervención estatal en la economía.

Sus socios más prominentes se vincularon, en sus inicios al Partido Unificación Nacional, que alcanzó el gobierno de la República en el período 1966-1970 bajo la administración Trejos Fernández. Luego se vincularon con el naciente Partido Unidad que alcanzó la presidencia de la República en el período 1978-1982, con Carazo Odio como presidente.

Para mediados de la década de los ochenta, la mayoría de los socios de la Academia de Centroamérica se adscribe al naciente Partido Unidad Social Cristiana y ocuparon posiciones relevantes en las administraciones Calderón Fournier (1990-1994) y Rodríguez Echeverría (1998-2002).

CEFSA, fundada en 1978, es una empresa de servicios de consultoría empresarial, formada por economistas y abogados, la mayoría vinculados al Partido Liberación Nacional, los cuales han dirigido algunas de las principales instituciones públicas del sector exportador y desde allí han favorecido las transformaciones principales del modelo de sustitución de importaciones al modelo de libre comercio.

Los socios de CEFSA se han desempeñado en distintos cargos públicos relacionados con el sector comercial, económico y exportador, y la mayoría de sus socios se expresaron políticamente en el Partido Liberación Nacional, ocupando cargos relevantes en las administraciones de Oscar Arias Sánchez (1986-1990 y 2006-2010), José María Figueres Olsen (19941998) y la actual de Laura Chinchilla Miranda (2010-2014).

CINDE, organización creada en 1983 , con generosos recursos de la Agencia para el Desarrollo Internacional (AID) de los Estados Unidos, incluyó desde su creación a representantes directos de las cámaras empresariales costarricenses, es decir, de la Cámara de Comercio, la Cámara de Industrias, la Cámara de Agricultura y posteriormente de la Cámara de Exportadores, así como socios de la Academia de Centroamérica y CEFSA, todos ellos integrantes de los partidos Liberación Nacional y Unidad Social Cristiana.

La investigación muestra consistentemente el despliegue de tales organizaciones, sus vínculos con los partidos políticos y cómo han articulado un conjunto de redes imbricadas de agentes público-privados en el rediseño y control de las instituciones públicas relacionadas con el sector exportador en el período comprendido entre 1986 y 2010. 
ASOCIADOS DE CINDE, ACADEMIA DE CENTROAMÉRICA Y CEFSA EN CARGOS PÚBLICOS RELACIONADOS CON EL SECTOR EXPORTADOR ADMINISTRACIÓN ARIAS SÁNCHEZ 1986-1990

\begin{tabular}{|c|c|c|c|c|c|c|c|c|}
\hline \multicolumn{9}{|c|}{ NOMBRAMIENTOS EN CARGOS PÚBLICOS RELACIONADOS CON EL SECTOR EXPORTADOR } \\
\hline $\begin{array}{l}\text { Eduardo } \\
\text { Lizano Fait, } \\
\text { Presidente } \\
\text { del Banco } \\
\text { Central }\end{array}$ & $\begin{array}{l}\text { Fernando } \\
\text { Naranjo } \\
\text { Villalobos, } \\
\text { Ministro de } \\
\text { Hacienda } \\
\text { 1986-1988 }\end{array}$ & $\begin{array}{l}\text { Rodrigo } \\
\text { Bolaños, } \\
\text { Ministro de } \\
\text { Hacienda } \\
\text { 1988-1990 }\end{array}$ & $\begin{array}{l}\text { Jorge } \\
\text { Woodbridge, } \\
\text { Ministro de } \\
\text { Economía, } \\
\text { Industria y } \\
\text { Comercio } \\
\text { 1986-1988 }\end{array}$ & $\begin{array}{l}\text { Antonio } \\
\text { Burgués } \\
\text { Terán, } \\
\text { Ministro de } \\
\text { Economía, } \\
\text { Industria y } \\
\text { Comercio } \\
\text { 1988-1990 }\end{array}$ & $\begin{array}{l}\text { Muni } \\
\text { Figueres } \\
\text { Boggs, } \\
\text { Ministra de } \\
\text { Comercio } \\
\text { Exterior } \\
\text { 1986-1988 }\end{array}$ & $\begin{array}{l}\text { José María } \\
\text { Figueres } \\
\text { Olsen, } \\
\text { Ministro de } \\
\text { Agricultura }\end{array}$ & $\begin{array}{l}\text { Luis Diego } \\
\text { Escalante, } \\
\text { Ministro de } \\
\text { Comercio } \\
\text { Exterior } \\
\text { 1988-1990 }\end{array}$ & $\begin{array}{l}\text { Mario } \\
\text { Carvajal } \\
\text { Herrera, } \\
\text { diputado }\end{array}$ \\
\hline
\end{tabular}

Fuente: elaboración propia, 2010.

ASOCIADOS DE CINDE Y DE LA ACADEMIA DE CENTROAMÉRICA EN CARGOS PÚBLICOS RELACIONADOS CON EL SECTOR EXPORTADOR ADMINISTRACIÓN CALDERÓN FOURNIER 1990-1994

NOMBRAMIENTOS EN CARGOS PÚBLICOS RELACIONADOS CON EL SECTOR EXPORTADOR

\begin{tabular}{|c|c|c|c|c|c|c|}
\hline $\begin{array}{l}\text { Leonel Baruch, } \\
\text { Director de } \\
\text { la Oficina } \\
\text { de toma de } \\
\text { decisiones de la } \\
\text { Presidencia de } \\
\text { la República }\end{array}$ & $\begin{array}{l}\text { Roberto Rojas } \\
\text { López, } \\
\text { Ministro de } \\
\text { Comercio } \\
\text { Exterior }\end{array}$ & $\begin{array}{l}\text { Juan Rafael } \\
\text { Lizano, } \\
\text { Ministro de } \\
\text { Agricultura }\end{array}$ & $\begin{array}{l}\text { Miguel Ángel } \\
\text { Rodríguez } \\
\text { Echeverría, } \\
\text { Diputado y } \\
\text { Presidente de } \\
\text { la Asamblea } \\
\text { Legislativa } \\
\text { 1991-1992 }\end{array}$ & $\begin{array}{l}\text { Thelmo Vargas } \\
\text { Madrigal, } \\
\text { Ministro de } \\
\text { Hacienda }\end{array}$ & $\begin{array}{l}\text { Jorge Guardia } \\
\text { Quirós, } \\
\text { Presidente del } \\
\text { Banco Central }\end{array}$ & $\begin{array}{l}\text { Claudio } \\
\text { González Vega, } \\
\text { Asesor del } \\
\text { Banco Central }\end{array}$ \\
\hline
\end{tabular}

Fuente:elaboración propia, 2010.

ASOCIADOS DE CINDE, ACADEMIA DE CENTROAMÉRICA Y CEFSA EN CARGOS PÚBLICOS RELACIONADOS CON EL SECTOR EXPORTADOR ADMINISTRACIÓN FIGUERES OLSEN 1994-1998

\begin{tabular}{|c|c|c|c|c|c|c|c|}
\hline \multicolumn{8}{|c|}{ NOMBRAMIENTOS EN CARGOS PÚBLICOS RELACIONADOS CON EL SECTOR EXPORTADOR } \\
\hline $\begin{array}{l}\text { José María } \\
\text { Figueres } \\
\text { Olsen, } \\
\text { Presidente } \\
\text { de la } \\
\text { República }\end{array}$ & $\begin{array}{l}\text { Rodrigo } \\
\text { Oreamuno } \\
\text { Blanco, Primer } \\
\text { Vicepresidente }\end{array}$ & $\begin{array}{l}\text { José Rossi } \\
\text { Umaña, } \\
\text { Ministro de } \\
\text { Comercio } \\
\text { Exterior }\end{array}$ & $\begin{array}{l}\text { Anabelle } \\
\text { González, } \\
\text { Jefa de } \\
\text { Negociaciones } \\
\text { Comerciales, } \\
\text { CoMEX }\end{array}$ & $\begin{array}{l}\text { Fernando } \\
\text { Naranjo } \\
\text { Villalobos, } \\
\text { Ministro de } \\
\text { Relaciones } \\
\text { Exteriores }\end{array}$ & $\begin{array}{l}\text { Rodrigo } \\
\text { Bolaños, } \\
\text { Presidente } \\
\text { del Banco } \\
\text { Central }\end{array}$ & $\begin{array}{l}\text { Federico } \\
\text { Vargas } \\
\text { Peralta, } \\
\text { Embajador } \\
\text { en } \\
\text { Washington }\end{array}$ & $\begin{array}{l}\text { Mario } \\
\text { Carvajal } \\
\text { Herrera, } \\
\text { Ministro de } \\
\text { Agricultura }\end{array}$ \\
\hline
\end{tabular}

Fuente: elaboración propia, 2010.

\section{ASOCIADOS DE CINDE Y LA ACADEMIA DE CENTROAMÉRICA EN CARGOS PÚBLICOS RELACIONADOS} CON EL SECTOR EXPORTADOR ADMINISTRACIÓN RODRÍGUEZ ECHEVERRÍA 1998-2002

\begin{tabular}{|c|c|c|c|c|c|c|c|c|}
\hline \multicolumn{9}{|c|}{ NOMBRAMIENTOS EN CARGOS PÚBLICOS RELACIONADOS CON EL SECTOR EXPORTADOR } \\
\hline $\begin{array}{l}\text { Miguel } \\
\text { Ángel } \\
\text { Rodríguez, } \\
\text { Presidente } \\
\text { de la } \\
\text { República }\end{array}$ & $\begin{array}{l}\text { Samuel } \\
\text { Guzowsky } \\
\text { Rose, } \\
\text { Ministro de } \\
\text { Economía } \\
\text { y de } \\
\text { Comercio } \\
\text { Exterior, } \\
\text { 1998-2000 }\end{array}$ & $\begin{array}{l}\text { Tomás } \\
\text { Dueñas, } \\
\text { Ministro de } \\
\text { Economía } \\
\text { y de } \\
\text { Comercio } \\
\text { Exterior, } \\
2000 \text { - } \\
2002\end{array}$ & $\begin{array}{l}\text { Anabelle } \\
\text { González, } \\
\text { Viceministra } \\
\text { de Comercio } \\
\text { Exterior }\end{array}$ & $\begin{array}{l}\text { Leonel } \\
\text { Baruch, } \\
\text { Ministro } \\
\text { de } \\
\text { Hacienda }\end{array}$ & $\begin{array}{l}\text { Edna } \\
\text { Camacho, } \\
\text { Viceministra } \\
\text { de Hacienda }\end{array}$ & $\begin{array}{l}\text { Eduardo } \\
\text { Lizano } \\
\text { Fait, } \\
\text { Presidente } \\
\text { Banco } \\
\text { Central }\end{array}$ & $\begin{array}{l}\text { Roberto } \\
\text { Rojas } \\
\text { López, } \\
\text { Ministro } \\
\text { Relaciones } \\
\text { Exteriores }\end{array}$ & $\begin{array}{l}\text { Juan } \\
\text { Rafael } \\
\text { Lizano, } \\
\text { Ministro } \\
\text { de } \\
\text { Seguridad }\end{array}$ \\
\hline
\end{tabular}

Fuente: elaboración propia, 2010. 


\section{ASOCIADOS DE CINDE Y LA ACADEMIA DE CENTROAMÉRICA \\ EN CARGOS PÚBLICOS RELACIONADOS CON EL SECTOR EXPORTADOR \\ ADMINISTRACIÓN PACHECO DE LA ESPRIELLA 2002-2006}

\begin{tabular}{|c|c|c|c|c|c|c|}
\hline \multicolumn{7}{|c|}{ NOMBRAMIENTOS EN CARGOS PÚBLICOS RELACIONADOS CON EL SECTOR EXPORTADOR } \\
\hline $\begin{array}{l}\text { Alberto } \\
\text { Trejos, } \\
\text { Ministro de } \\
\text { Comercio } \\
\text { Exterior }\end{array}$ & $\begin{array}{l}\text { Vilma Villalobos } \\
\text { Carvajal, } \\
\text { Viceministra } \\
\text { y Ministra de } \\
\text { Economía }\end{array}$ & $\begin{array}{l}\text { Jorge Walter } \\
\text { Bolaños, } \\
\text { Ministro de } \\
\text { Hacienda }\end{array}$ & $\begin{array}{l}\text { Anabelle González, } \\
\text { Jefa de Negociadores } \\
\text { del Tratado de Libre } \\
\text { Comercio }\end{array}$ & $\begin{array}{l}\text { Ronulfo } \\
\text { Jiménez, } \\
\text { Coordinador } \\
\text { del equipo } \\
\text { económico }\end{array}$ & $\begin{array}{l}\text { Gabriela } \\
\text { Llobet, } \\
\text { Viceministra } \\
\text { de Comercio } \\
\text { Exterior }\end{array}$ & $\begin{array}{l}\text { Alberto Dent, } \\
\text { Ministro de } \\
\text { Hacienda }\end{array}$ \\
\hline
\end{tabular}

Fuente: elaboración propia, 2010.

ASOCIADOS DE CINDE Y EL INCAE EN CARGOS PÚBLICOS RELACIONADOS CON EL SECTOR EXPORTADOR ADMINISTRACIÓN ARIAS SÁNCHEZ 2006-2010

\begin{tabular}{|c|c|c|c|c|c|c|}
\hline \multicolumn{7}{|c|}{ NOMBRAMIENTOS EN CARGOS PÚBLICOS RELACIONADOS CON EL SECTOR EXPORTADOR } \\
\hline $\begin{array}{l}\text { Francisco } \\
\text { de Paula } \\
\text { Gutiérrez, } \\
\text { Presidente del } \\
\text { Banco Central }\end{array}$ & $\begin{array}{l}\text { Marco Vinicio } \\
\text { Ruiz, } \\
\text { Ministro de } \\
\text { Comercio } \\
\text { Exterior }\end{array}$ & $\begin{array}{l}\text { Jorge } \\
\text { Woodbridge, } \\
\text { Asesor en } \\
\text { competitividad } \\
\text { con rango de } \\
\text { Ministro }\end{array}$ & $\begin{array}{l}\text { Tomás Dueñas, } \\
\text { Embajador en } \\
\text { Washington } \\
2006-2009\end{array}$ & $\begin{array}{l}\text { Antonio } \\
\text { Burgués Terán, } \\
\text { Embajador en } \\
\text { China }\end{array}$ & $\begin{array}{l}\text { Mayi Antillón, } \\
\text { Ministra de } \\
\text { Comunicación } \\
\text { y diputada }\end{array}$ & $\begin{array}{l}\text { Luis Diego } \\
\text { Escalante, } \\
\text { Embajador en } \\
\text { Washington } \\
2009-2010\end{array}$ \\
\hline
\end{tabular}

Fuente: elaboración propia, 2010.

ASOCIADOS DE CINDE, CEFSA Y ACADEMIA DE CENTROAMÉRICA EN CARGOS PÚBLICOS RELACIONADOS CON EL SECTOR EXPORTADOR ADMINISTRACIÓN CHINCHILLA MIRANDA 2010-2014

\begin{tabular}{|c|c|c|c|c|c|c|}
\hline \multicolumn{7}{|c|}{ NOMBRAMIENTOS EN CARGOS PÚBLICOS RELACIONADOS CON EL SECTOR EXPORTADOR } \\
\hline $\begin{array}{l}\text { Rodrigo } \\
\text { Bolaños, } \\
\text { Presidente del } \\
\text { Banco Central }\end{array}$ & $\begin{array}{l}\text { Anabel } \\
\text { González, } \\
\text { Ministra de } \\
\text { Comercio } \\
\text { Exterior }\end{array}$ & $\begin{array}{l}\text { Luis } \\
\text { Libermann, } \\
\text { Primer } \\
\text { Vicepresidente }\end{array}$ & $\begin{array}{l}\text { Muni Figueres, } \\
\text { Embajadora en } \\
\text { Washington } \\
2006-2009\end{array}$ & $\begin{array}{l}\text { Marco Vinicio } \\
\text { Ruiz, } \\
\text { Embajador en } \\
\text { China }\end{array}$ & $\begin{array}{l}\text { Mayi Antillón, } \\
\text { Ministra de } \\
\text { Economía }\end{array}$ & $\begin{array}{l}\text { Fernando } \\
\text { Naranjo, } \\
\text { Gerente } \\
\text { del Banco } \\
\text { Nacional }\end{array}$ \\
\hline
\end{tabular}

Fuente: Elaboración propia, 2010.

\section{A MANERA DE CONCLUSIONES}

Este artículo propone un acercamiento al estudio de los partidos políticos como organizaciones complejas, tal como lo proponen Panebianco y Katz y Mair.

En el período estudiado, los partidos Liberación Nacional y Unidad Social Cristiana, han sido una especie de canales de intermediación entre las redes corporativas y el acceso a los puestos de decisión del sector exportador, integrando a sus asociados a los gabinetes del poder ejecutivo y facilitando un control monopólico de legitimidades, recursos institucionales $y$ presupuestarios, que permiten a tales grupos corporativos los mecanismos necesarios para hacer prevalecer sus intereses sectoriales como interés general.

En el sector exportador existe un control monopólico de las instituciones públicas por parte de los socios de CINDE - alianza sui generis de cámaras empresariales-y dos redes de tecnócratas que han influenciado decididamente la transformación del aparato exportador costarricense en los últimos 24 años.

La colectividad termina subvencionando con recursos públicos el grueso de decisiones políticas y de políticas públicas que solo benefician al pequeño sector exportador costarricense. Y ello es posible, porque el sistema 
presidencialista costarricense faculta al poder ejecutivo a nombrar en los cargos -que no son de elección popular- a quiénes el presidente considere como los idóneos para ejercer tales responsabilidades. En la totalidad de los nombramientos estudiados, los socios de CINDE, de CEFSA, de la Academia de Centroamérica y de las cámaras empresariales han terminado controlando las instituciones del sector exportador, proponiendo hasta la creación de leyes, programas y políticas de beneficio corporativo.

En todos los casos, se puede apreciar la facilidad con que acuerdos bipartidistas entre 1986 y 2010 viabilizaron tales resultados, sin ningún tipo de control ciudadano sobre tales decisiones. Porque al permitirse que los partidos políticos funcionen en la perspectiva disociada de partidos de élites y partidos atrapalotodo (Pallavicini, 2009: 15) han conducido a un resultado conflictivo entre las expectativas crecientes de electorados prebendarios $y$ los resultados muy concretos que benefician a sectores corporativos de claro corte neoliberal.

Acciones como, reducir la democracia a un procedimiento, aceptar una separación entre los procedimientos de nombramiento de gobernantes y el ejercicio del poder sin reconocer o apelar, al mismo tiempo, a la necesidad de crear condiciones sociales e institucionales para el ejercicio de los derechos individuales y sociales, con capacidad de control político $y$ de exigibilidad, garantizar a los ciudadanos autonomía para actuar con otros y frente a las instituciones, supone la necesidad de revisar las formas cuasimonopólicas con que los sectores corporativos han venido usufructuando de los bienes públicos y hasta de las organizaciones partidarias costarricenses.

El peligro fundamental de tales reduccionismos es la elitización y oligarquización de las decisiones por grupos corporativos, que controlando las estructuras de selección de los partidos políticos y dónde solo se autorreferencian ante ellos mismos, sin que existan mecanismos de control social, jurídico y político que les exija, enjuicie y controle por sus actuaciones; pueden terminar convirtiéndose en el principal obstáculo para procesos efectivos de profundización de la vida democrática en Costa Rica.
De estas fracturas estructurales se crean condiciones para el rechazo de las acciones que busquen extender $y$ profundizar la democracia $y$ este contexto, bien podría explicar el origen de todo "notablismo" o "meritocratismo", que elitiza y favorece los discursos sobre la necesidad de "líderes fuertes", que "ellos si salvan a la Patria" del nuevo "director de orquesta", del "líder carismático" y tantas fórmulas de cariz autocrático y napoleónico. Es decir, de nuevo más autoritarismo y menos democracia.

Finalmente, quisiera llamar la atención sobre un conjunto de interrogantes que quedan abiertas para profundizar la perspectiva aquí planteada:

1. ¿Cómo democratizar los partidos políticos costarricenses, cuyas dinámicas internas han facilitado la entronización de las redes corporativas dentro de sus instancias de decisión?

2. ¿Cómo seguir hablando de democratización de partidos políticos dejando intactas prácticas internas basadas en caudillismos, personalismos, influencias corporativas y con un marcado estilo de gestión electoral prebendario $y$ clientelar?

3. ¿Cómo contribuir con procesos de profundización de la vida democrática en Costa Rica, dejando intactas — dentro de los partidos políticos - culturas elitistas $y$ corporativistas que amparados en un sistema presidencialista, prácticamente imposibilitan cualquier mecanismo de transformación interna?

4. ¿Cómo se puede seguir apelando a una retórica de perfeccionamiento de los "mecanismos electorales" o de la "ingeniería electoral", sin discutir a fondo los límites de los procesos de corporativización de los partidos políticos?

5. ¿Se puede seguir apelando a la existencia de una democracia representativa $y$ participativa — como tanto se pregonacontando las principales estructuras políticas, que han dominado el aparato 
estatal los últimos 25 años, con tales redes corporativas en su interior?

El estudio propuesto bien podría ayudar a responder tales interrogantes, al entender a los partidos políticos como organizaciones complejas, visibilizando los efectos de las redes de poder dentro de los partidos en una perspectiva histórica y su despliegue de influencias al controlar las capacidades de decisión de sectores completos del aparato estatal, estudiando la conformación de los gabinetes.

\section{BIBLIOGRAFÍA}

Aguilar Villanueva, Luis. Problemas públicos y agenda de gobierno. México: Porrúa Editorial, 2003.

Alcántara Sáez, Manuel. Partidos políticos latinoamericanos. ¿Instituciones o máquinas ideológicas? Barcelona: Ediciones Gérnika, 2004.

Blanco Lizano, Randall. "Reformas neocorporativas $y$ disputas por el control de los recursos biogenéticos en la constitución del campo político de la biodiversidad en Costa Rica 1989-2003". [Tesis de Maestría en Sociología]. Universidad de Costa Rica, 2004.

Blanco Lizano, Randall. "Transformaciones del sector exportador costarricense en la transición del modelo de sustitución de importaciones al modelo de libre comercio: 1982-1996 estudio de caso de las redes imbricadas de agentes públicoprivados: CINDE-COMEX". [Tesis Doctoral en el Programa de Gobierno y Políticas Públicas]. Universidad de Costa Rica, 2010a.

Blanco Lizano, Randall. "Tendencias corporativas en las transformaciones del Estado costarricense 1983-2008. Estudio comparativo de los sectores ambiental y exportador". Ponencia presentada al XII Congreso Centroamericano de Sociología, agosto de $2010 \mathrm{~b}$.
Bourdieu, Pierre. Razones prácticas. Sobre la teoría de la acción. Barcelona: Editorial Anagrama, 1997.

Cavarozzi, Marcelo y Abal Medina, Juan Manuel. El asedio a la política. Los partidos latinoamericanos en la era neoliberal. Rosario: Homo Sapiens Ediciones, 2002.

DEMUCA. Ingeniería y comportamientos electorales a nivel municipal. San José: DEMUCA, 2009.

Easton, David. El sistema político. Buenos Aires: Amorrotu, 1979.

Elias, Norbert. Sociología Fundamental. España: Gedisa Ediciones, 1982.

Grindle, Merilee y Thomas, John. Public Choices and Policy Change. The political economy of reform in developing countries. Baltimore: John Hopkins University, 1991.

Guzmán, Juany y Jiménez González, Luis. La toma de la democracia: nuevos retos para la sociedad civil y la élite política de Centroamérica. San José: Lara Segura \& Asociados Editores, 2005.

IIDH. Democratización interna de partidos politicos en Centroamérica. Avances y tareas pendientes. San José: IIDH, 2004.

Lindblom, Charles. El proceso de elaboración de politicas públicas. Madrid: Ministerio para las Administraciones Públicas, 1991.

Molina Alfaro, Eugenia. "Estrategias de socialización profesional y política pública: el caso del equipo negociador del TLC con Estados Unidos". [Tesis Doctoral en Ciencias Sociales]. Guatemala: FLACSO, 2009.

Pallavicini, Violeta. "Ingeniería electoral. Marco conceptual”. En: DEMUCA. Ingeniería y comportamientos electorales a nivel municipal. San José: DEMUCA, 2009.

Perelli, Carina; Picado, Sonia y Zovatto, Daniel. Partidos y clase politica en América Latina en los 90. San José: IIDH-CAPEL, 1995.

Raventós Vorst, Ciska. "Democracia y proceso de aprobación de las políticas de ajuste 1980-1995". En: Jorge Rovira Mas (editor). La democracia de Costa Rica 
ante el siglo XXI. San José: Editorial Universidad de Costa Rica, 2001.

Raventós Vorst, Ciska. "Abstención: conceptos $y$ alcances, problemas asociados $y$ posibilidades de superación. Perspectiva política". Ponencia presentada en la XVII Conferencia Protocolo de Tikal. San José, Costa Rica. 2003.

Raventós Vorst, Ciska et ál. Abstencionistas en Costa Rica. ¿Quiénes son y por qué no votan?. San José: Editorial Universidad de Costa Rica, IIDH-CAPEL. 2006.

Rovira Mas, Jorge. Elecciones en Costa Rica 1998. ¿Se debilita el bipartidismo?. San José: Instituto de Investigaciones Sociales, Universidad de Costa Rica, 1998.

Sojo, Carlos. La utopía del Estado mínimo. Influencia de la AID en Costa Rica en los años ochenta. Managua: CRIES, 1991.

Sojo, Carlos. La mano visible del mercado. La asistencia de Estados Unidos al sector privado costarricense en la década de los ochenta. Managua: CRIES, 1992.

Solís Avendaño, Manuel. "Entre el cambio y la tradición: el fracaso de la privatización de la energía y las telecomunicaciones en Costa Rica". Revista de Ciencias Sociales 95 (I). Universidad de Costa Rica, 2002: 33-47.

Shepsle, Kenneth y Bonchek, Mark. Las fórmulas de la politica. Instituciones, racionalidad y comportamiento. México: Taurus, 2005.

Vásquez Rodríguez, Jorge. "Costa Rica. El neocorporativismo empresarial político en el actual estilo de desarrollo: el caso de la Promotora de Comercio Exterior PROCOMER". [Tesis de Maestría en Sociología]. Universidad de Costa Rica, 2008.

Villasuso, Juan Manuel. "Procesos electorales y política económica en Costa Rica”. En: Jorge Rovira Mas (editor). La democracia de Costa Rica ante el Siglo XXI. San José: Editorial de la Universidad de Costa RicaInstituto de Investigaciones SocialesFundación Friedrich Ebert, 2001.

Fecha de ingreso: 08/04/2011 Fecha de aprobación: 25/04/2011 